Supporting Information

\title{
Magnetic Nanoplatform for Covalent Protein Immobilization Based on Spy Chemistry
}

Xiuyu Jin† $\dagger^{\mathrm{a}}$, Quanhui Ye $\dagger^{\mathrm{b}}$, Chien-Wei Wang ${ }^{\mathrm{b}}$, Ying $\mathrm{Wu}^{\mathrm{b}}$, Kangling $\mathrm{Ma}^{\mathrm{a}}$, Sihan $\mathrm{Yu}^{\mathrm{c}}, \mathrm{Na}$ Wei*b and Haifeng Gao*a

$\dagger$ These authors contributed equally

a. Department of Chemistry and Biochemistry, University of Notre Dame, Notre Dame, Indiana 46556, United States

b. Department of Civil and Environmental Engineering and Earth Sciences, University of Notre Dame, Notre Dame, Indiana 46556, United States

c. Department of Chemical and Bioengineering, University of Notre Dame, Notre Dame, Indiana 46556, United States

*E-mail: nwei@nd.edu, hgao@,nd.edu

\section{Experimental Section}

Materials. All chemicals and solvents were purchased and used as received: $\mathrm{FeCl}_{3} \bullet$ $6 \mathrm{H}_{2} \mathrm{O}(97 \%$, Beantown Chemical), trisodium citrate (99\%, Alfa Aesar), sodium acetate (99\%, Alfa Aesar), tetraethoxysilane (TEOS, $\geqslant 96 \%$, TCI), 3-aminopropyltriethoxysilane (APTES, $\geqslant 96 \%$, TCI), ethylene glycol (99.0\%, BDH Chemical), ethanol (200PRF, KOPTEC), tetrahydrofuran (THF, 99\%, J.T.Baker), 2-bromoisobutyryl bromide (97\%, Sigma-Aldrich), 
triethylamine (TEA, 97\%, ACROS Organics), dimethylformamide (DMF, J.T.Baker), 1,1,4,7,10,10-hexamethyltriethylenetetramine (HMTETA, 97\%, Sigma-Aldrich), $\mathrm{CuBr} 2$ (99\%, Sigma-Aldrich), 2,2'-azobisisobutyronitrile (AIBN, 98\%, Sigma-Aldrich), allyl bromide (99\%, Alfa Aesar), hydrofluoric acid (48\%, Sigma-Aldrich), fluorescamine (HPLC grade, TCI), trifluoroacetic acid (99.9\%, Chem-impex), triisopropylsilane (TIPS, > 99\%, Chem-Impex), Rink amide AM resin (0.67 meq/g, Chem-Impex). All protected peptides for Fmoc solid-phase peptide synthesis (SPPS) were purchased from Chem-Impex. 2.2'-Dimethylaminoethyl methacrylate (DMAEMA, 99\%, TCI) was purified by passing through basic alumina column to remove inhibitors. $\mathrm{CuBr}(99 \%$, Sigma-Aldrich) was purified by washing with glacial acetic acid under $36{ }^{\circ} \mathrm{C}$ overnight, followed by filtration and rinsing with methanol 3 times and dehydration in a vacuum oven.

Strains, Medium, and Chemicals for Cloning. Escherichia coli TOP10 strain (Invitrogen) was used for gene cloning and manipulation. Recombinant E. coli cells were cultured in Luria-Bertani (LB) medium at $37{ }^{\circ} \mathrm{C}$, with $100 \mathrm{mg} / \mathrm{L}$ of ampicillin added to the medium when required. E. coli BL21 (F-ompT gal dcm lon $\mathrm{hsdS}_{\mathrm{B}}\left(\mathrm{rB}^{-} \mathrm{mB}^{-}\right) \lambda(\mathrm{DE} 3)$ [lacI lac

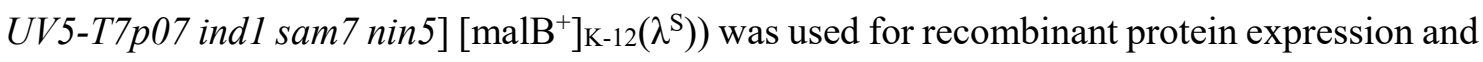
purification. Restriction enzymes, ligase, and molecular reagents for gene cloning were obtained from New England Biolabs (Beverly, MA). Primers for polymerase chain reaction (PCR) were synthesized by Integrated DNA Technologies (Coralville, IA). All other general chemicals and medium components were supplied by Fisher Scientific (Pittsburgh, PA).

Synthesis of BrTEOS. To synthesize 3-(2-bromoisobutyramido) propyl(triethoxy)silane (BrTEOS), 2-bromoisobutyryl bromide $(2.5 \mathrm{~mL}, 20 \mathrm{mmol})$ was added 
dropwise to a mixed solution (in ice-bath) containing 3-aminopropyltriethoxysilane $(3.75 \mathrm{~mL}$, $16 \mathrm{mmol})$, TEA $(2.8 \mathrm{~mL}, 20 \mathrm{mmol})$ and anhydrous THF $(25 \mathrm{~mL})$. The reaction was conducted under magnetic stirring at room temperature for $3 \mathrm{~h}$. Then the reaction mixture was transferred to a $50 \mathrm{~mL}$ tube and the salt sediments were separated by centrifugation at $3000 \mathrm{rpm}$ for 10 minutes. Filtrated supernatant was further evaporated under vacuum at $30{ }^{\circ} \mathrm{C}$ to remove THF and TEA, and unreacted 2-bromoisobutyryl bromide have been removed by filtration before rotary evaporation. The triethylammonium bromide precipitated during rotary evaporation was removed completely from the viscous silane by centrifugation. The resulting purified organosilane compound was stored at $4{ }^{\circ} \mathrm{C} .(5.4 \mathrm{~g}$, yield $=95 \%)$.
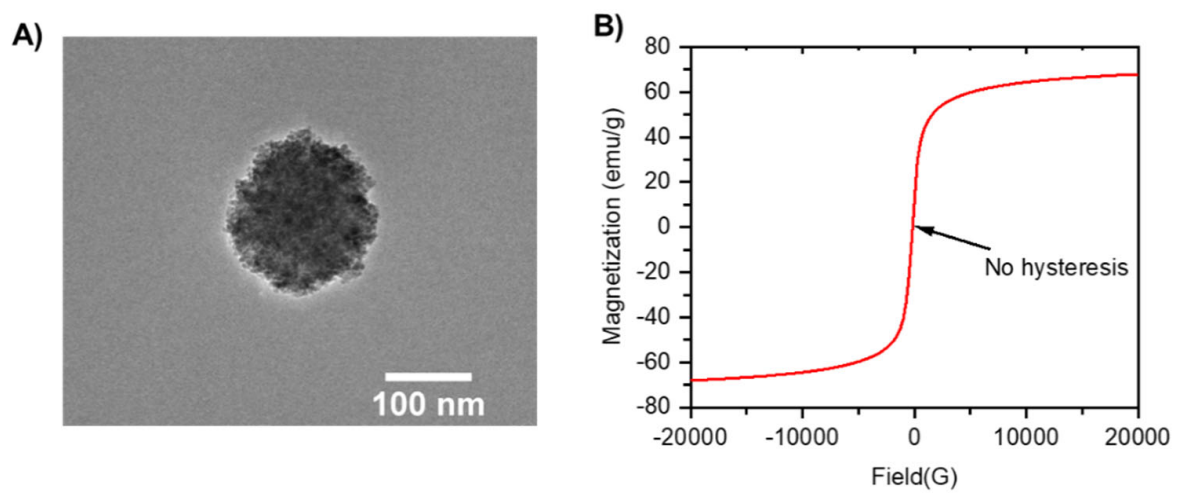

Figure S1. A) TEM image of MNP1. B) Magnetic hysteresis loop of MNP1 showing no magnetic hysteresis. 


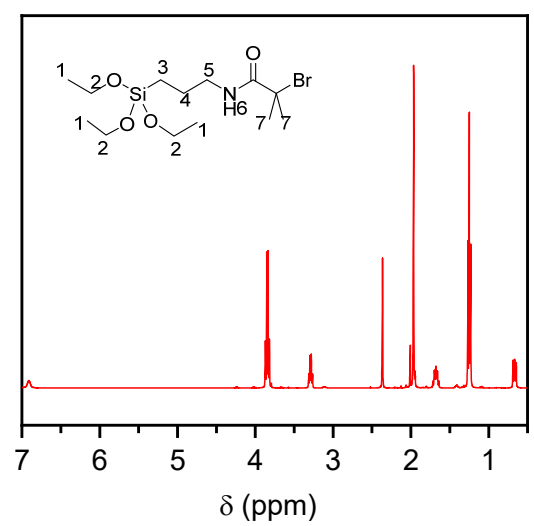

Figure S2. ${ }^{1} \mathrm{H}-\mathrm{NMR}\left(400 \mathrm{MHz}, \mathrm{CDCl}_{3}\right)$ of BrTEOS: $\mathrm{H}_{6}: \mathrm{d} 6.91$ (s, 1H); H2: d 3.85 (q, 6H); H5: d 3.29 (m, 2H); H7: d 1.96 (s, 6H); H4: d 1.67 (m, 2H); H1: d 1.25 (t,9H); H3: d 0.67 (t, 2H).

Synthesis of $\mathrm{Fe}_{3} \mathrm{O}_{4} @ \mathrm{SiO}_{2}-\mathrm{Br} . \mathrm{Fe} 3 \mathrm{O} 4 @ \mathrm{SiO} 2-\mathrm{Br}(\mathrm{MNP} 4)$ was prepared through coating a silica layer onto the magnetic MNPs using a Stober sol-gel method. Typically, $1.00 \mathrm{~g}$ of $\mathrm{Fe}_{3} \mathrm{O}_{4}$ seeds (MNP1) were suspended in the mixture of $400 \mathrm{ml}$ of ethanol, $50 \mathrm{ml}$ of deionized water, and $12 \mathrm{ml}$ of $28 \mathrm{wt} \%$ ammonium hydroxide aqueous solution under ultrasonication. TEOS in $2 \mathrm{ml}$ was added under mechanical stirring and sonication at room temperature for 4.5 h. BrTEOS $(150 \mu \mathrm{L})$ diluted in $3 \mathrm{ml}$ ethanol was then added by syringe pump in $30 \mathrm{~min}$. The reaction mixture was stirred without sonication for another $12 \mathrm{~h}$. The resulting MNP4 particles were washed 3 time with ethanol before being freeze-dried. 


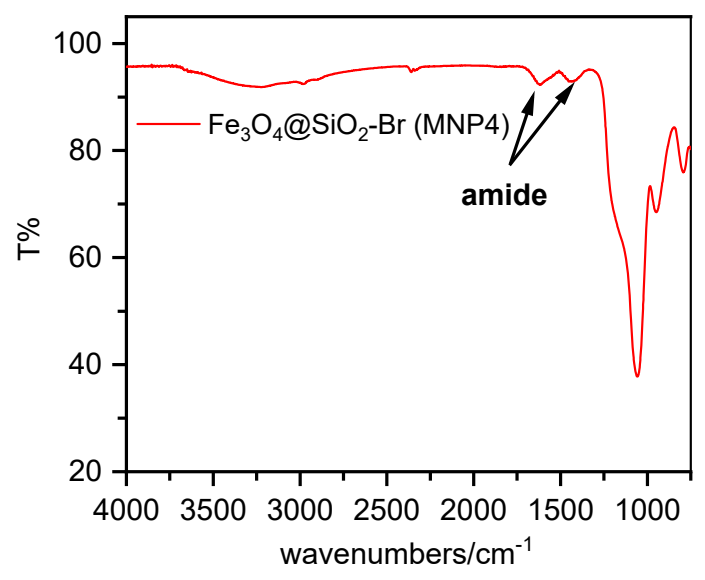

Figure S3. ATR-FTIR spectrum of MNP4 after initiator functionalization.

Synthesis of SpyTag. Cysteine-terminated SpyTag (CGGGGS-AHIVMVDAYKPTK) was synthesized by Fmoc-SPPS. Chain-extension was conducted in a peptide synthesizer (Liberty Blue CEM Corporation), with a typical synthesis scale of SpyTag of $0.5 \mathrm{mmol}$. After reaction, the rink amide beads with conjugated SpyTag were taken out, washed 3 times with DMF and DCM, then cleavage cocktail (prepared by mixing $15 \mathrm{~mL}$ TFA, $0.33 \mathrm{~mL} \mathrm{H}_{2} \mathrm{O}$ and $0.33 \mathrm{~mL}$ TIPS for protection) was added and incubated with a shaking for 3 hours. After that, the beads were washed twice with $15 \mathrm{~mL}$ cleavage solution and DCM, respectively. Drained solution was collected before reducing the solution volume to $5 \mathrm{~mL}$ in a rotary evaporator. Products were precipitated in $40 \mathrm{~mL}$ cold ethyl ether and washed twice with $40 \mathrm{~mL}$ cold ethyl ether. Precipitated raw products was left in hood overnight to allow the evaporation of ether residues and obtained yellow solid were further purified using Biotage flash chromatography with water/acetonitrile gradient as the mobile phase. The fractions of CV15 to CV17 were collected and lyophilized to obtain the purified product $(0.180 \mathrm{~g}$, yield $=19.0 \%)$. Pure product should be white powder. 


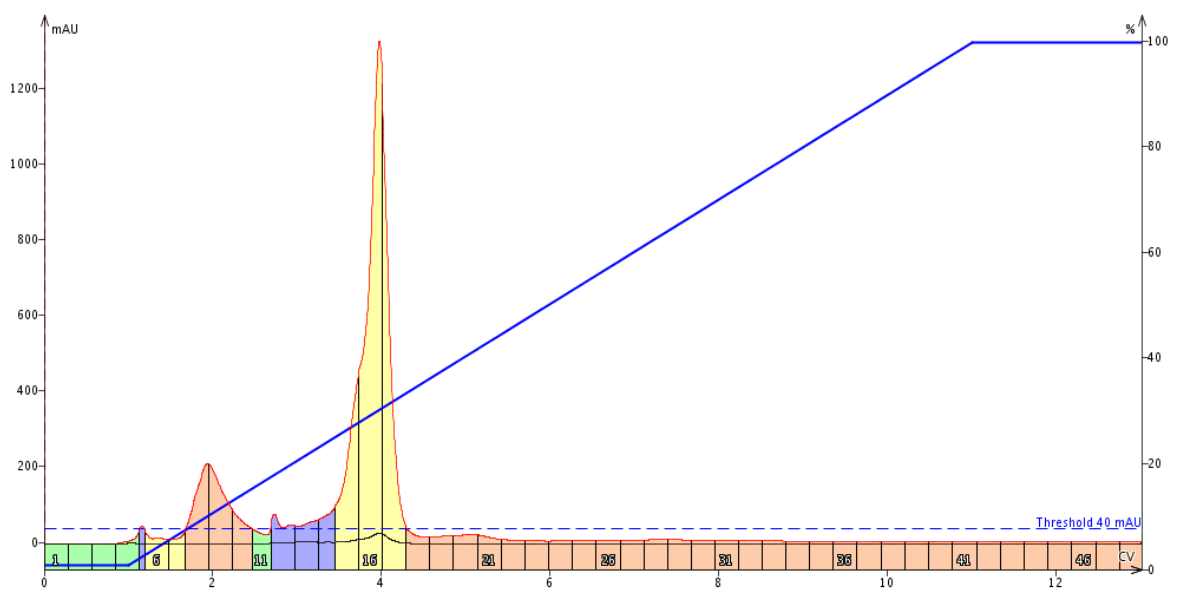

Figure S4. Biotage flash chromatography elution diagram of raw SpyTag in acetonitrile/water. Sample from CV15 to CV17 were collected. Red line: UV response of eluted fraction. Blue line: relevant acetonitrile water ratio. Sfar Bio Duo C18 column (50 g) was used and the flow rate was set to $70 \mathrm{~mL} / \mathrm{min}$.

Model Reaction Between SpyTag and Allyl Alcohol. In a $10 \mathrm{~mL}$ Schlenk flask, $1 \mathrm{~mL}$ SpyTag solution in DMF $(10 \mathrm{mg} / \mathrm{mL})$ was mixed with $10 \mu \mathrm{L}$ allyl alcohol and $10 \mathrm{mg}$ AIBN. After being degassed by 3 freeze-pump-thaw cycles, the flask was sealed, and the reaction was proceeded at $70{ }^{\circ} \mathrm{C}$ for $72 \mathrm{~h}$ under vigorous magnetic stirring. The product was precipitated in cold ether, collected by centrifugation, washed 3 times with cold ether before being redispersed in water. Purified product was further obtained by lyophilization.

Synthesis of $\mathrm{Fe}_{3} \mathrm{O}_{4} @ \mathrm{SiO}_{2}$-vinyl (MNP2). Similar to the synthesis of MNP4, MNP2 was also prepared using a Stober sol-gel method. Briefly, $1.00 \mathrm{~g}$ of $\mathrm{Fe}_{3} \mathrm{O}_{4}$ seeds were suspended in the mixture of $400 \mathrm{ml}$ of ethanol, $50 \mathrm{ml}$ of deionized water, and $12 \mathrm{ml}$ of $28 \mathrm{wt} \%$ ammonium hydroxide aqueous solution. TEOS in $2 \mathrm{ml}$ was added under mechanical stirring and sonication at room temperature for $4.5 \mathrm{~h}$. Vinyltrimethoxysilane (VTMS, $100 \mu \mathrm{L}$ ) diluted in $3 \mathrm{ml}$ ethanol 
was then added by syringe pump in $30 \mathrm{~min}$. The reaction mixture was stirred without sonication for another $12 \mathrm{~h}$. The resulting MNP2 particles were washed 3 times with ethanol before being freeze-dried.

Synthesis of $\mathrm{Fe}_{3} \mathrm{O}_{4} @ \mathrm{SiO}_{2} @ S T$ (MNP3). To fabricate MNP3 without polymer shell, SpyTag was conjugated directly to the surface of MNP-vinyl through thiol-ene reaction. Specifically, $10 \mathrm{mg}$ SpyTag was mixed with $100 \mathrm{mg}$ MNP2 in $5 \mathrm{~mL}$ DMF in a Schlenk flask. After adding $10 \mathrm{mg}$ AIBN into the reaction and getting flask sealed, the reaction mixture was degassed by 3 freeze-pump-thaw cycles before elevating the temperature to $70^{\circ} \mathrm{C}$. The reaction was conducted for 24 hours under magnetic stirring before opening the flask and cooling the reaction to room temperature. The resulting MNP3 particles in reaction mixture were washed by DMF and ethanol for 3 times.



Figure S5. A) Synthesis route of MNP2 and MNP3. B) Hydrodynamic size of MNP2 and MNP3 in DI water. C) Zeta potential of MNP2 and MNP3. 
Synthesis of $\mathrm{Fe}_{3} \mathrm{O}_{4} @ \mathrm{SiO}_{2} @ P D M A E M A(M N P 5$ and MNP6). MNP5 and MNP6 was synthesized from MNP4 using surface-initiated atom transfer radical polymerization (SIATRP). In a typical polymerization reaction, $300 \mathrm{mg} \mathrm{MNP} 4,30 \mu \mathrm{L}$ HMTETA, $1.00 \mathrm{~mL}$ DMAEMA, $2.00 \mathrm{~mL}$ DMF, $1.00 \mathrm{~mL} \mathrm{H}_{2} \mathrm{O}$, and $2.5 \mathrm{mg} \mathrm{CuBr} 2$ were added to a $10 \mathrm{~mL}$ Schlenk flask. The mixture was sonicated for 10 mins before being sealed and deoxygenated by 3 freeze-pump-thaw cycles. In the frozen state, $7 \mathrm{mg} \mathrm{CuBr}$ was added under protection of $\mathrm{N}_{2}$ flow. The flask was quickly frozen under liquid $\mathrm{N}_{2}$ before the frozen mixture was subjected to 3 pump- $\mathrm{N}_{2}$ backfilling cycles. The reaction mixture was ultimately thawed and immersed in an oil batch at $40{ }^{\circ} \mathrm{C}$ with magnetic stirring for polymerization of 12 hours. The resulting MNP particles in reaction mixture were washed by acetone and water for 3 times before freeze-dried.

Synthesis of $\mathrm{Fe}_{3} \mathrm{O}_{4} @ \mathrm{SiO}_{2} @$ PQDMAEMA (MNP7 and MNP8). A typical procedure for the synthesis of MNP7 was described below. MNP5 in $0.200 \mathrm{~g}$ (polymer $\mathrm{w} \%=47.5 \%$ ) was dispersed in $5 \mathrm{~mL}$ DMF under ultrasonication to form MNP dispersion. $1 \mathrm{~mL}$ allyl bromide was then added to MNP dispersion. Reaction was set up at room temperature under argon atmosphere and magnetic stirring for $24 \mathrm{~h}$. The resulting MNP7 could be easily precipitated by adding $30 \mathrm{~mL}$ acetone, which is a bad solvent for charged polymers. Products were collected by centrifugation and washed 3 times with acetone, and then redispersed in DMF for further use. To synthesize MNP8, a similar procedure was used, with MNP6 as the precursor instead.

Synthesis of $\mathrm{Fe}_{3} \mathrm{O}_{4} @ \mathrm{SiO}_{2} @$ PQDMAEMA/ST (MNP9, MNP10 and MNP11). In a typical synthesis of MNP9, $2 \mathrm{~mL}$ SpyTag solution in DMF $(10 \mathrm{mg} / \mathrm{mL})$ was mixed with 300 mg MNP7 in $4 \mathrm{~mL}$ DMF dispersion. This mixture was further diluted to $8 \mathrm{~mL}$ by DMF before 
being charged in a $10 \mathrm{~mL}$ Schlenk flask equipped with a magnetic stirring bar. After adding 40 mg AIBN, the flask was sealed and the solution was degassed by 3 freeze-pump-thaw cycles. The reaction was proceeded at $70{ }^{\circ} \mathrm{C}$ for $72 \mathrm{~h}$ under vigorous magnetic stirring. The product was collected by centrifugation, washed 3 times with DMF before being redispersed in DMF for further use. By adjusting the feed ratio of SpyTag to different MNP precursors, three samples in large amount ( $>200 \mathrm{mg}$, Table S1) were prepared and termed as MNP9, MNP10 and MNP11, which contained $2.34 \mathrm{w} \%, 8.70 \mathrm{w} \%$, and $7.30 \mathrm{w} \%$ of SpyTag, respectively. 
Table S1. Information on different batches of MNPs with conjugated SpyTag. Note: MNP91 and $\mathrm{MNP9}^{2}$ were combined to obtain MNP9 (2.34 w\% of SpyTag) for further use.

\begin{tabular}{|c|c|c|c|c|c|c|}
\hline Entry & $\begin{array}{c}\text { MNP } \\
\text { precursor }^{\mathrm{a}}\end{array}$ & $\mathbf{A I B N}^{\mathbf{a}}$ & SpyTaga $^{a}$ & $\begin{array}{l}\text { SpyTag conc. } \\
\text { Before reaction }\end{array}$ & $\begin{array}{l}\text { SpyTag conc. } \\
\text { after reaction }^{\mathfrak{c}}\end{array}$ & $\begin{array}{l}\text { SpyTag w\% } \\
\text { in product }\end{array}$ \\
\hline MNP9 $^{1}$ & $\mathrm{MNP7}, 300 \mathrm{mg}$ & $40 \mathrm{mg}$ & $20 \mathrm{mg}$ & $2.50 \mathrm{mg} / \mathrm{mL}$ & $1.65 \mathrm{mg} / \mathrm{mL}$ & 2.23 \\
\hline $\mathrm{MNP9}^{2}$ & $\mathrm{MNP7}, 300 \mathrm{mg}$ & $40 \mathrm{mg}$ & $20 \mathrm{mg}$ & $2.50 \mathrm{mg} / \mathrm{mL}$ & $1.56 \mathrm{mg} / \mathrm{mL}$ & 2.45 \\
\hline MNP10 & MNP7, $200 \mathrm{mg}$ & $50 \mathrm{mg}$ & $39 \mathrm{mg}$ & $4.90 \mathrm{mg} / \mathrm{mL}$ & $2.50 \mathrm{mg} / \mathrm{mL}$ & 8.70 \\
\hline MNP11 & MNP8, $200 \mathrm{mg}$ & $50 \mathrm{mg}$ & $42 \mathrm{mg}$ & $5.20 \mathrm{mg} / \mathrm{mL}$ & $3.28 \mathrm{mg} / \mathrm{mL}$ & 7.30 \\
\hline
\end{tabular}

a. Feed amount of reactants for thiol-ene click conjugation. b. SpyTag concentration in reaction solution (total vol. $=8 \mathrm{~mL}$ ) before initiating the reaction. Calculated by weight. c. SpyTag concentration in reaction solution (total vol. $=8 \mathrm{~mL}$ ) after $24 \mathrm{~h}$ reaction. Evaluated by fluorescamine assay.

Quantification of SpyTag immobilized to MNP. Fluorescamine assay was used to quantify the amount of remaining SpyTag in solution after thiol-ene coupling reaction between cysteine-terminated SpyTag and the vinyl-containing MNPs. Accordingly, the amount of immobilized SpyTag could be calculated by subtraction from the initial SpyTag amount. Basically, fluorescamine (I) quantitatively reacts with primary amine group to generate fluorescent compound (II, Figure S6). The SpyTag peptide synthesized in this study has three $-\mathrm{NH}_{2}$ groups. Standard calibration curve was prepared using a series of SpyTag solutions with concentrations ranging from $100 \mu \mathrm{g} / \mathrm{mL}$ to $1000 \mu \mathrm{g} / \mathrm{mL}$ in $100 \mathrm{mM}$ PBS buffer, $\mathrm{pH}$ 7.4. Fluorescamine solution $(3 \mathrm{mg} / \mathrm{mL})$ was prepared by dissolving fluorescamine in acetone. In a 96-well plate, $150 \mu \mathrm{L}$ of cysteine-SpyTag solution and $50 \mu \mathrm{L}$ fluorescamine solution were mixed in each well. After 15-min incubation, the fluorescence intensity was recorded by a plate reader (Infinite M200 PRO, Tecan) with an excitation wavelength of $280 \mathrm{~nm}$ and an emission 
wavelength of $480 \mathrm{~nm}$.

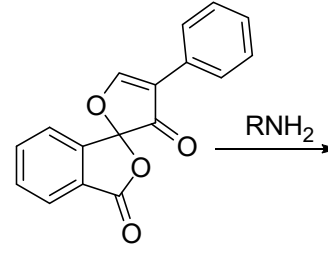

[l] Fluorescamine

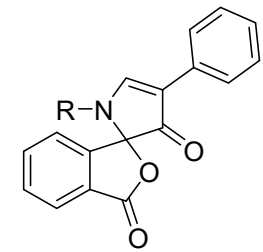

[II] Fluorescent compound

Figure S6. Fluorescamine assay reaction with primary amine to turn on fluorescence.

To determine the amount of free Spytag after thiol-ene reaction, the reaction mixture was centrifuged (9500 rpm, $20 \mathrm{~min}$ ) and the supernatant was used for fluorescamine assay (Figure S7). Briefly, the supernatant was diluted 5 times with a PBS buffer, mixed with $50 \mu \mathrm{L}$ of fluorescamine solution in a 96-well plate. After 15-min incubation, the fluorescence intensity was measured and subtracted from that of PBS buffer. The concentration of free SpyTag was calculated accordingly. All measurements were conducted in triplicate.

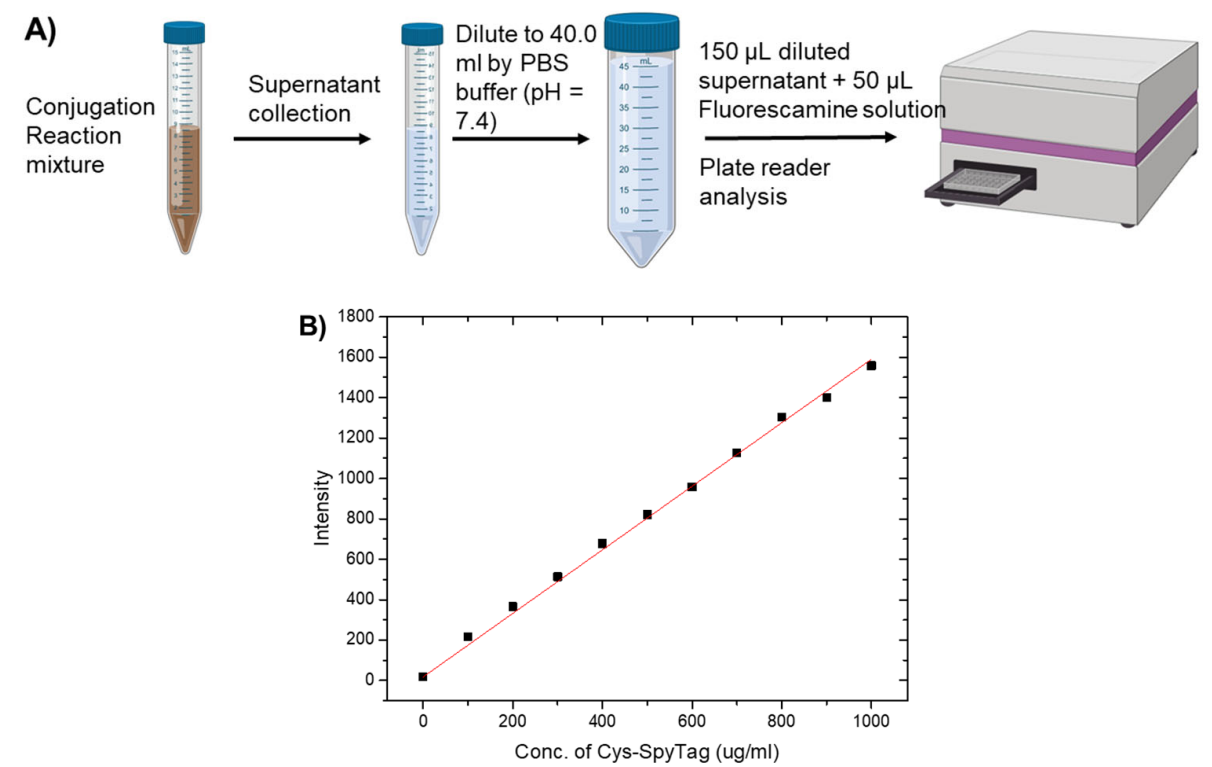

Figure S7. (A) Typical procedure for quantification of SpyTag in the reaction solution. (B) A standard curve between fluorescence intensity and SpyTag concentration. 
Spectroscopic Characterization of MNPs. Transmission electron microscopy (TEM) images were performed with a JEOL-2011 TEM with an acceleration voltage of $200 \mathrm{kV}$. Sample solutions were dispersed on ultrathin carbon-supported copper grids. ${ }^{1} \mathrm{H}-\mathrm{NMR}$ spectra were obtained from Bruker AVANCE III HD 400 Nanobay. Absorption spectra of MNP dispersions were measured on Thermo Scientific GENESYSTM 140 Visible Light Spectrophotometer. The magnetic property was characterized using a MPMS ${ }^{\circledR}$ superconducting quantum interference device (SQUID, Quantum Design, San Diego, CA). The hydrodynamic size and zeta potential distribution of the samples were obtained from Zetasizer Nano-ZS (He-Ne laser wavelength at $633 \mathrm{~nm}$ ). Thermal gravimetric analysis was carried out on TGA/DSC-1 STAR ${ }^{\mathrm{e}}$ system (Mettler Toledo). ATR-FTIR spectra were measured by JASCO FT/IR 6300 spectrometer.

Magnetic Responsiveness Measurement in Solution. Magnetic responsiveness of MNPs in aqueous media was characterized by the evolution of absorption of the MNP dispersion when an external magnetic field was applied. Typically, $1 \mathrm{mg}$ MNP dispersed in 1 $\mathrm{mL}$ dioninzed water was loaded to a $10 \mathrm{~mm}$ polystyrene cuvette, then the loaded cuvette was placed on a N52 magnet (40 mm x $40 \mathrm{~mm}$ x $20 \mathrm{~mm})$. Evolution of absorption of MNP dispersion (OD600) was tracked by a visible spectrophotometer based on the assumption that the absorption of MNP dispersion is proportional to the concentration of MNP. 


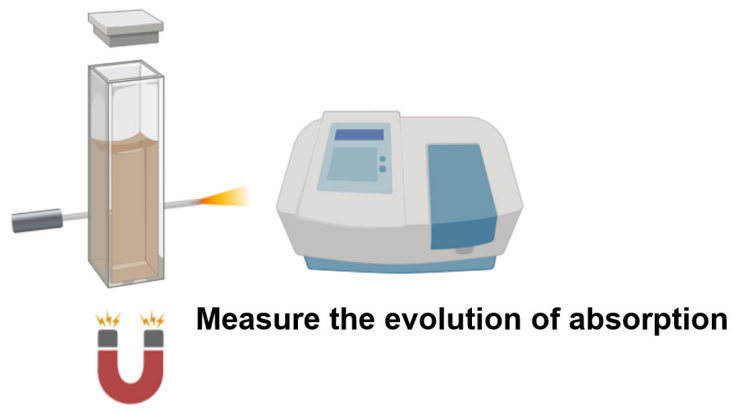

Figure S8. Using spectrophotometer to characterize the mobility of MNPs in the presence of an external magnetic field.

Construction, Expression, and Purification of SpyCatcher-fused EGFP. The strains, plasmids, and primers in this study are listed in Table S2. The encoding gene for enhanced green fluorescent protein (EGFP) from Aequorea Victoria was generated by PCR with pcDNA3-EGFP plasmid (Addgene, plasmid \#13031) as the template and the SpyCatcher (SC) gene from Streptococcus pyogenes was amplified by PCR with pDEST14-SpyCatcher (Addgene, plasmid \#35044) as the template. Next, the fusion protein cassette, which contains coding sequences of EGFP and SpyCatcher, was cloned into pET21b (+) vector with a His6tag at the C terminus, yielding pET21b-EGFP-SpyCatcher (Fig. S9). The resulting recombinant plasmid was transformed into E. coli TOP10 competent cells, which were selected on LB agar plates containing $100 \mathrm{mg} / \mathrm{L}$ ampicillin, followed by plasmid extraction using QIAprep Spin Miniprep Kit (QIAGEN Inc., Germantown, MD). The recombinant plasmid was confirmed by Sanger sequencing and stored at $-20{ }^{\circ} \mathrm{C}$ before further uses. 
Table S2. The strains, plasmids, and primers used in this study

\begin{tabular}{|c|c|c|}
\hline $\begin{array}{l}\text { Plasmid/strain/pri } \\
\text { mers }\end{array}$ & Description & Reference \\
\hline Plasmids & & \\
\hline pcDNA3-EGFP & Plasmid template for the PCR amplification of EGFP & Addgene \\
\hline pDEST14- & Plasmid template for the PCR amplification of & Literature $^{1}$ \\
\hline SpyCatcher & SpyCatcher & \\
\hline pET21b $(+)$ & $\begin{array}{l}\text { Expression vector for the construction of recombinant } \\
\text { EGFP and SpyCatcher }\end{array}$ & Novagen \\
\hline pET21b-EGFP- & EGFP and SpyCatcher fusion protein gene sequence & This study \\
\hline SpyCatcher & expressed in pET21b $(+)$ & \\
\hline Strains & & \\
\hline Escherichia coli & E. coli competent cells for molecular cloning and & Invitrogen \\
\hline TOP 10 & manipulation & \\
\hline Escherichia coli & E. coli competent cells for fusion protein expression & it \\
\hline BL21 (DE3) & and purification & \\
\hline Primer & Primer sequence (listed 5' to $3^{\prime}$ ) & \\
\hline Forward primer for & & \\
\hline $\begin{array}{l}\text { EGFP amplification } \\
\text { with NdeI restriction }\end{array}$ & GGGGCATATGATGGTGAGCAAGGGC & This study \\
\hline
\end{tabular}


Continued

Plasmid/strain/primers Description

Reference

Reverse primer for EGFP

amplification with BamHI

GGGGGGATCCCTTGTACAGCTCGTCCA This study

restriction site

Forward primer for

SpyCatcher amplification GGGGGGATCCGTTGATACCTTATCAGGT

TTATCAA

This study

with BamHI restriction site

Reverse primer for

SpyCatcher amplification GGGGCTCGAGAATATGAGCGTCACCTTT

AG

This study

with XhoI restriction site
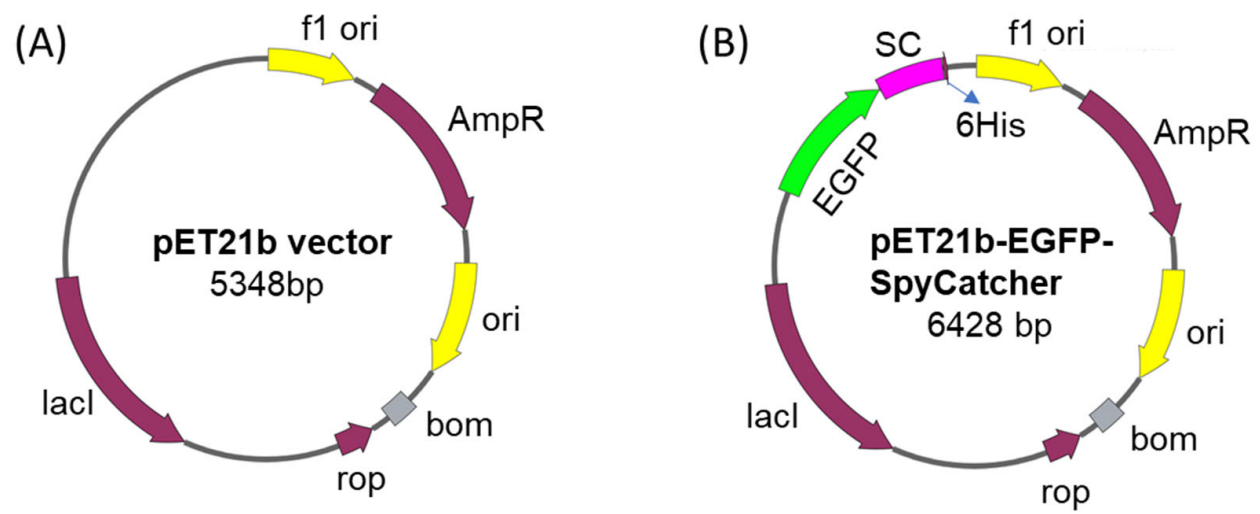

Figure S9. Schematics of the plasmids: (A) pET21b (+); (B) pET21b-EGFP-SpyCatcher.

The confirmed plasmid was transformed into E. Coli BL21(DE3) competent cells for the recombinant protein (i.e., EGFP-SpyCatcher) expression and purification. In brief, $5 \mathrm{~mL}$ of 
overnight culture of the recombinant cells was transferred into $1 \mathrm{~L}$ fresh LB growth media containing $100 \mathrm{mg} / \mathrm{L}$ ampicillin and incubated at $37{ }^{\circ} \mathrm{C}$ with vigorous shaking $(250 \mathrm{rpm})$ until the optical density at the wavelength of $600 \mathrm{~nm}\left(\mathrm{OD}_{600}\right)$ reached 0.6-0.8. Protein induction was achieved by an addition of $100 \mu \mathrm{M}$ isopropyl- $\beta$-d-thiogalactopytanoside (IPTG). After a further incubation for 5 hours, the induced cells were harvested through centrifugation (15 mins, 5000 $\mathrm{rpm}$ ), and the pellets were resuspended in protein lysis buffer (50 mM Tris- $\mathrm{HCl}, 150 \mathrm{mM} \mathrm{NaCl}$, $10 \mathrm{mM}$ imidazole, $\mathrm{pH}$ 7.4) supplemented with appropriate EDTA-free Protease Inhibitor Cocktail (Sigma Aldrich, St. Louis, MO), and then were sonicated $40 \times 15 \mathrm{~s}$ on/off pulse cycle at 30 watt. After cell lysis, the cell lysate was centrifuged at $13000 \mathrm{rpm}$ for $15 \mathrm{mins}$ to remove cell debris, and the recombinant protein in cleared supernatant was purified using HisPur ${ }^{\mathrm{TM}} \mathrm{Ni}-$ NTA Purification Kit (Thermofisher, USA) according to manufacturer's instructions. All protein purification steps were carried out at $4{ }^{\circ} \mathrm{C}$. The eluted recombinant protein was confirmed through sodium dodecyl sulphate-polyacrylamide gel electrophoresis (SDS-PAGE) and Coomassie staining (Fig. S9). Briefly, protein samples were separated in $12 \%$ polyacrylamide gels using a Mini-PROTEAN Tetra Cell (Bio-Rad, USA) at $120 \mathrm{~V}$ for approximately 2 hrs., Gels were stained with Brilliant Blue G solution (Sigma Aldrich, St. Louis, MO) and destained in $25 \%(\mathrm{v} / \mathrm{v})$ ethanol and $10 \%(\mathrm{v} / \mathrm{v})$ acetic acid overnight. The confirmed recombinant protein was then concentrated and dialyzed three times into $50 \mathrm{mM}$ Tris-buffered saline (TBS), pH 7.0 using Vivaspin 6 centrifugal concentrator (GE Healthcare, USA). Protein concentration was determined using bicinchoninic acid (BCA) Assay kit (Thermo Scientific, USA) following manufacturer's instructions. 


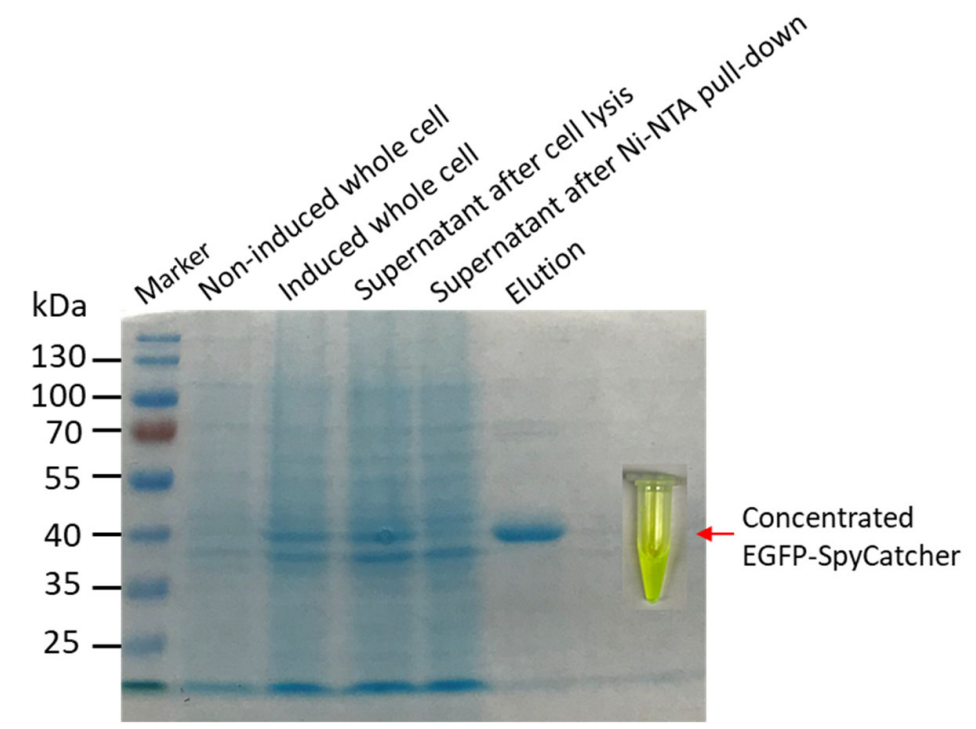

Figure S10. SDS-PAGE of EGFP-SpyCatcher purified by nickel nitrilotriacetic acid (Ni-

NTA) column.

Table S3. Mass balance of EGFP-SpyCatcher conjugation in TBS buffer at the 5:1 feed molar ratio of SpyTag:SpyCatcher

\begin{tabular}{lllllll}
\hline & Initial & Supernatant & Wash 1 & Wash 2 & Wash 3-7 & EGFP on \\
MNP sample & $(\mu \mathrm{g})$ & $(\mu \mathrm{g})$ & $(\mu \mathrm{g})$ & $(\mu \mathrm{g})$ & $(\mu \mathrm{g})$ & MNPs $(\mu \mathrm{g})$ \\
\hline Control MNP & & & & & & \\
(MNP7) & $99.1 \pm 4.6$ & $76.6 \pm 6.8$ & $18.4 \pm 1.1$ & $1.6 \pm 0.1$ & $0.4 \pm 0.03$ & $0.3 \pm 0.1$ \\
MNP9 & $99.1 \pm 4.6$ & $3.3 \pm 0.3$ & $6.4 \pm 0.2$ & $3.4 \pm 0.1$ & $5.6 \pm 0.12$ & $73.5 \pm 3.3$ \\
\hline
\end{tabular}

Conjugation of EGFP-SpyCatcher onto MNPs. Feasibility of conjugating EGFPSpyCatcher onto MNPs with SpyTag (MNP9 and MNP10) was tested by incubating MNP with EGFP-SpyCatcher in $50 \mathrm{mM}$ TBS, pH 7.0 overnight at room temperature under constant 
shaking at a SpyTag:SpyCatcher molar ratio of 5:1. The control MNP without SpyTag modification (MNP7, 0\% ST) was incubated with EGFP-SpyCatcher in parallel. Another control sample (MNP3) without polymer corona was also conjugated with EGFP-SpyCatcher. To remove nonspecific protein immobilization on MNP, the MNP was washed three times with TBS containing $250 \mathrm{mM}$ imidazole, three times with TBS containing $0.5 \%(\mathrm{v} / \mathrm{v})$ Tween 20, and one time with TBS. The MNP was separated and harvested by magnetic rack or centrifugation (9000 rpm, 3 mins), and resuspended in TBS buffer before further analyses. All conjugation experiments were conducted in triplicate.

\section{Fluorescence Microscope Imaging and EGFP-SpyCatcher Fluorescent Intensity}

Measurement. To clearly see the successful conjugation, MNP7 and MNP9 after EGFPSpyCatcher conjugation were diluted in TBS buffer $(500 \mathrm{ng} / \mu \mathrm{L})$ and observed under a UVBOX (inset in Figure 3B). To confirm the localization of EGFP-SpyCatcher on MNP, the conjugated MNP (e.g., MNP9) was visualized on an Eclipse 90i fluorescence microscope (Nikon Instruments Inc., Melville, NY). The green fluorescence signals were detected using a UMWIG2 mirror unit with a BP460-490 excitation filter, and a DM505 dichroic mirror with a BA510IF emission filter (Olympus). Images were analyzed with MetaMorph software (MDS, Inc, Sunnyvale, CA) and ImageJ. EGFP-SpyCatcher loading on MNP was quantified by a Synergy $^{\text {TM }}$ H1 microplate reader (BioTek, Winooski, VT) by measuring green fluorescence intensity of MNP9 and MNP10 at the excitation and emission wavelength of 488 and $520 \mathrm{~nm}$, respectively. Briefly, the conjugated $\mathrm{MNP}$ after a full wash was diluted to $100 \mathrm{ng}-\mathrm{MNP} / \mu \mathrm{L}-$ buffer using TBS buffer and then $10 \mu \mathrm{L}$ of diluted MNP solution (i.e., $1 \mu \mathrm{g}$ MNP in total) was used to measure fluorescence intensity (note that $1 \mu \mathrm{g}$ MNP does not interfere with 
fluorescence detection). The fluorescence intensity of blank control (i.e., TBS buffer) was determined and subtracted from each measurement. Fluorescence intensity of EGFPSpyCatcher on MNP via SpyTag/SpyCatcher chemistry was calculated by subtracting fluorescent intensity of negative control MNP7 from that of MNP9 or MNP10, and EGFPSpyCatcher loading ( $\mu$ g-EGFP-SpyCatcher/mg-MNP) was calculated through a standard curve between EGFP-SpyCatcher quantity and fluorescent intensity. All measurements were performed in triplicate.

\section{Covalent Interaction between EGFP-SpyCatcher and SpyTag-incorporated MNP.}

To confirm that chemically synthesized SpyTag is able to react with SpyCatcher domain, SpyTag peptide and EGFP-SpyCatcher were incubated in $50 \mathrm{mM}$ TBS buffer, $\mathrm{pH} 7.0$ overnight at $4{ }^{\circ} \mathrm{C}$ under constant shaking at a SpyTag:SpyCatcher molar ratio of $1: 1$. The formation of EGFP-SpyCatcher:SpyTag covalent complex was confirmed by SDS-PAGE and Coomassie staining. To demonstrate that conjugation of EGFP-SpyCatcher onto MNP (e.g., MNP9) will not be influenced by nonionic detergents (e.g., Tween 20), the conjugation was also performed in TBS buffer containing 0.5\% (v/v) Tween 20, and EGFP-SpyCatcher loading was determined and compared to that achieved using TBS buffer. To further confirm that the conjugation is through SpyTag:SpyCatcher interaction, a mixture of EGFP-SpyCatcher and bovine serum albumin (BSA) was simultaneously incubated with MNP9 in $50 \mathrm{mM}$ TBS buffer, pH 7.0 at a ST: SC molar ratio of 5:1 and a ST: BSA molar ratio of 5:1. The control MNP were incubated with the same amount of protein mixture in parallel. EGFP-SpyCatcher loading on MNP9 was determined and compared to that achieved with individual EGFP-SpyCatcher. Also, supernatants from centrifugation of the conjugation solutions and the first two washing steps 
were separately collected and analyzed using SDS-PAGE and Coomassie staining.

Fluorescent Property and Stability of Conjugated EGFP. To determine whether the conjugation process will alter fluorescent properties of EGFP-SpyCatcher, emission and excitation spectra of both conjugated EGFP-SpyCatcher on MNP and free EGFP-SpyCatcher were examined using a Synergy ${ }^{\mathrm{TM}} \mathrm{H} 1$ microplate reader. Briefly, to obtain the emission spectra, $1 \mu \mathrm{g}$ EGFP-conjugated MNP (i.e., MNP9-EGFP) dispersed in TBS buffer or equivalent quantity of free EGFP-SpyCatcher in TBS buffer were scanned at an emission spectrum of 450 - $600 \mathrm{~nm}$, with the excitation wavelength at $418 \mathrm{~nm}$. The excitation spectra were obtained through scanning MNP-EGFP and free protein at an excitation spectrum of $350-500 \mathrm{~nm}$, with the emission wavelength fixed at $530 \mathrm{~nm}$, respectively. Additionally, stability of conjugated EGFP-SpyCatcher on MNP and free EGFP-SpyCatcher was determined by measuring the change in fluorescent intensity of equivalent amount of conjugated and free EGFP-SpyCatcher. Specifically, fluorescent intensity of $1 \mu \mathrm{g}$ MNP9-EGFP was firstly measured to determine EGFP-SpyCatcher loading on MNP, and an equivalent amount free EGFP-SpyCatcher was prepared in TBS buffer. The conjugated MNP9-EGFP and free EGFP-SpyCatcher were then incubated at room temperature for $1 \mathrm{~d}$ and $3 \mathrm{~d}$. To determine the change in fluorescent intensity of conjugated EGFP-SpyCatcher, the MNP was washed once with TBS (i.e., to wash off the leaking EGFP-SpyCatcher) and resuspended in TBS for fluorescence intensity quantification as described above. For free EGFP-SpyCatcher, its fluorescence intensity was directly examined after an appropriate dilution. To reveal the change in fluorescence intensity of free EGFP-SpyCatcher, the free EGFP-SpyCatcher in TBS buffer before and after incubation was observed under a UVBOX (inset in Figure 4D). 
Analytical Methods. $\mathrm{OD}_{600}$ was measured using an UV-visible spectrophotometer (Thermo Fisher Scientific Inc., Waltham, MA). Significant differences in EGFP-SpyCatcher loading on MNP9 (2.34 w\% ST) obtained from EGFP-SpyCatcher incubated with MNP9 in TBS buffer, in TBS buffer spiked with BSA at a ST:BSA molar ratio of 5:1, and in TBS buffer containing $0.5 \%(\mathrm{v} / \mathrm{v})$ Tween 20 were performed using one-way analysis of variance (ANOVA) and Tukey's post hoc test.
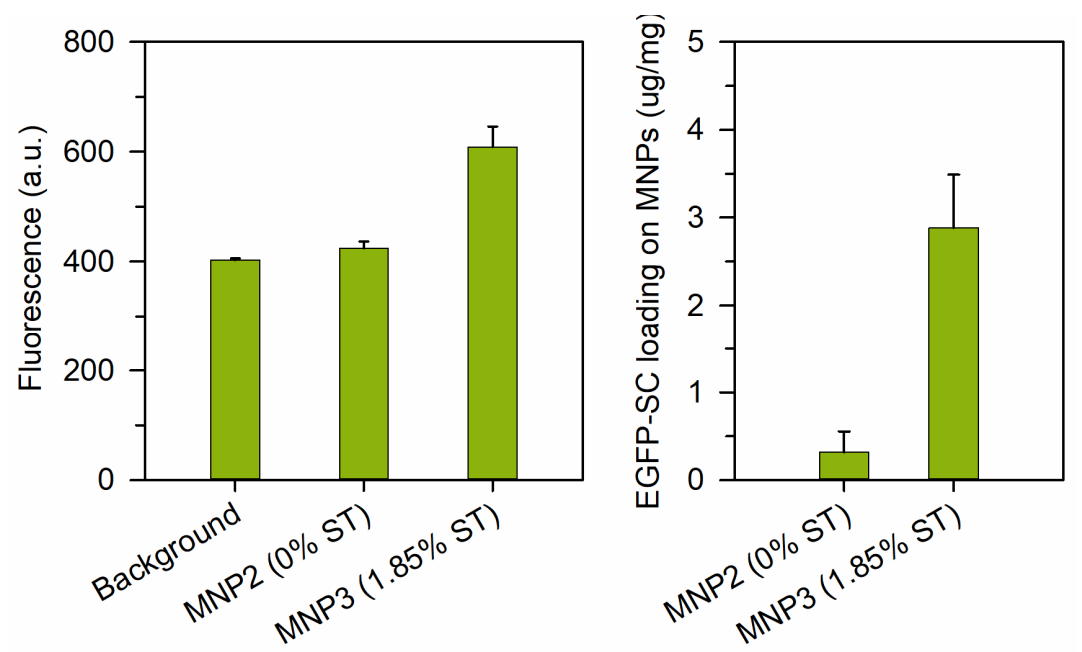

Figure S11. Fluorescence intensity of EGFP-SpyCatcher conjugated MNP2 and MNP3. Background binding of MNP2 is limited. The MNP3 could conjugate limited amount of EGFPSpyCatcher, however the capacity is much lower than samples with polymer grafting. 


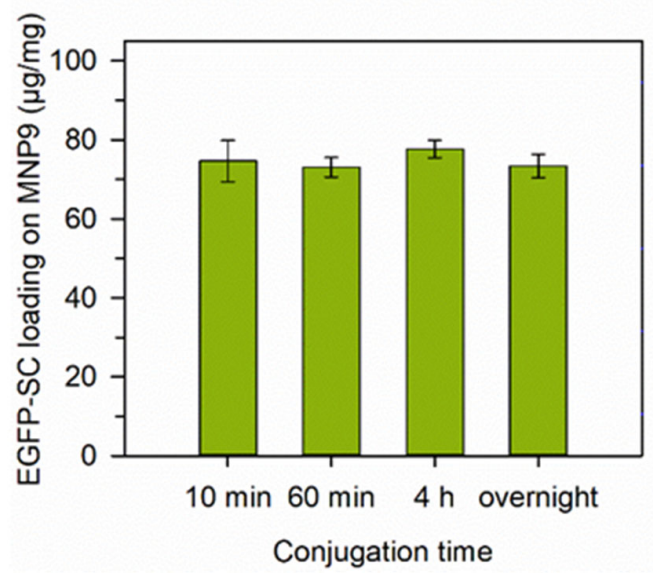

Figure S12. EGFP-SpyCatcher loading on MNP9 at different timed intervals in a typical conjugation (TBS buffer pH 7.0, SpyTag:SpyCatcher = 5:1).

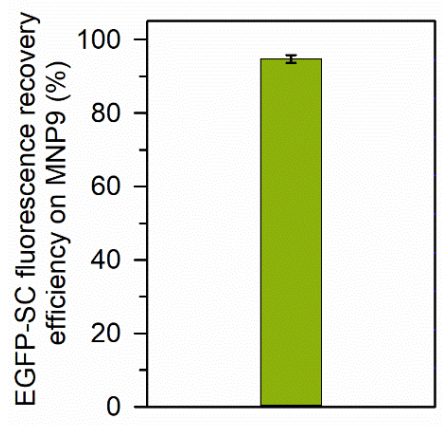

Figure S13. EGFP-SpyCatcher fluorescence recovery efficiency on MNP9. 


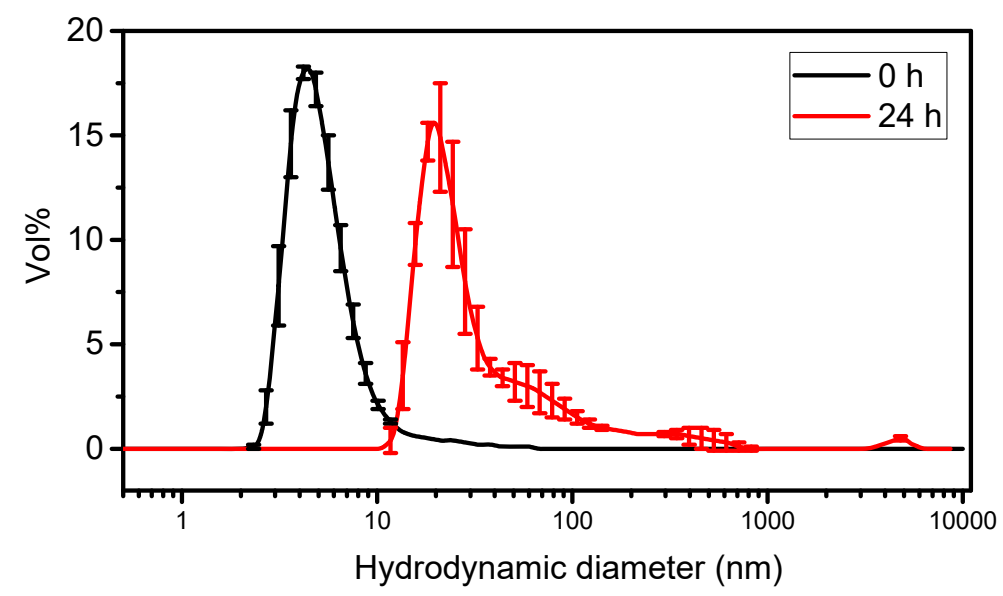

Figure S14. Hydrodynamic size evolution of free EGFP-SpyCatcher in TBS buffer $(\mathrm{pH}=$ 7.4, room temperature).

\section{References}

1. Zakeri, B.; Fierer, J. O.; Celik, E.; Chittock, E. C.; Schwarz-Linek, U.; Moy, V. T.; Howarth, M., Peptide Tag Forming a Rapid Covalent Bond to a Protein, Through Engineering a Bacterial Adhesin. Proc Natl Acad Sci U S A 2012, 109, E690-7. 